\title{
Testosterone in ancient hair from an extinct species
}

Koren, Lee; Matas, Devorah; Penerová, Patrícia; Dalén, Love; Tikhonov, Alexei; Gilbert, M. Thomas P.; Wynne-edwards, Katherine E.; Geffen, Eli

Published in:

Special Papers in Palaeontology

DOI:

10.1111/pala.2018.61.issue-6

Publication date:

2018

Document version

Publisher's PDF, also known as Version of record

Document license:

CC BY

Citation for published version (APA):

Koren, L., Matas, D., Penerová, P., Dalén, L., Tikhonov, A., Gilbert, M. T. P., Wynne-edwards, K. E., \& Geffen, E. (2018). Testosterone in ancient hair from an extinct species. Special Papers in Palaeontology, 61(6), 797802. https://doi.org/10.1111/pala.2018.61.issue-6 


\section{RAPID COMMUNICATION}

\section{TESTOSTERONE IN ANCIENT HAIR FROM AN EXTINCT SPECIES}

by LEE KOREN $^{1}$ (D, DEVORAH MATAS ${ }^{1}$, PATRÍCIA PEČNEROVÁ ${ }^{2,3}$, LOVE DALÉN $^{2}$, ALEXEI TIKHONOV ${ }^{4}$, M. THOMAS P. GILBERT ${ }^{5}$, KATHERINE E. WYNNE-EDWARDS ${ }^{6}$ and ELI GEFFEN ${ }^{7}$

${ }^{1}$ Faculty of Life Sciences, Bar Ilan University, Ramat Gan, Israel; lee.koren@biu.ac.il

${ }^{2}$ Department of Bioinformatics \& Genetics, Swedish Museum of Natural History, Stockholm, Sweden

${ }^{3}$ Department of Zoology, Stockholm University, Stockholm, Sweden

${ }^{4}$ Zoological Institute, Russian Academy of Sciences, Moskva, Russia

${ }^{5}$ Centre for GeoGenetics, Natural History Museum of Denmark, University of Copenhagen, Copenhagen, Denmark

${ }^{6}$ Faculty of Veterinary Medicine \& Hotchkiss Brain Institute, University of Calgary, Calgary, AB Canada

${ }^{7}$ School of Zoology, Tel Aviv University, Tel Aviv, Israel

Typescript received 24 October 2017; accepted in revised form 5 July 2018

Abstract: Testosterone is a key regulator in vertebrate development, physiology and behaviour. Whereas technology allows extraction of a wealth of genetic information from extant as well as extinct species, complementary information on steroid hormone levels may add a social, sexual and environmental context. Hair shafts have been previously used to sequence DNA from $>50000{ }^{14} \mathrm{C}$ years old Siberian woolly mammoths (Mammuthus primigenius). Hair-testing has also been used to measure endogenous steroids in multiple extant species. Here we use small quantities of woolly mammoth hair samples to measure testosterone, and a genomics-based approach to determine sex, in permafrost-preserved mammoths dated to c. $10000-60000{ }^{14} \mathrm{C}$ years. Our validated method opens up exciting opportunities to measure multiple steroids in keratinized tissues from extinct populations of mammals. This may be specifically applied to investigating life histories, including the extinct Quaternary megafauna populations whose remains are preserved in the permafrost throughout the northern hemisphere.

Key words: testosterone, endogenous steroids, hair-testing, woolly mammoth.
STEROID hormones play a fundamental role in the regulation of development, physiology, reproduction and behaviour. For example, progesterone and testosterone can provide information on reproductive state, such as a pregnancy or an age class. Testosterone is also involved in social processes, including parental behaviour, social status formation, risk-taking behaviour, sexual displays and mating (Ketterson \& Nolan 1999; Muller 2017). When elevated systemically, testosterone can have profound effects on fitness, often increasing reproductive success at the expense of survival and parental care (Dufty 1989; Paternostro 1994; Reed et al. 2006). Thus, testosterone levels may provide an insight on socio-environmental conditions that shape outcomes for individuals, groups and populations.

Traditionally, endogenous testosterone has been measured in the circulation through blood samples. However, this matrix is not available for extinct species. Hair, on the other hand, is more resilient in withstanding the wear and tear of time. Hair samples have been used for genetic analysis, with DNA sequenced from $>50000{ }^{14} \mathrm{C}$ year old Siberian mammoths (Mammuthus primigenius) (Gilbert et al. 2007, 2008). In the same study, DNA was also extracted from hair of a specimen that had been kept in room temperature for over 200 years. Hair-testing for steroids has been used in extant species (e.g. Koren et al. 2002, 2008; Koren \& Geffen 2009; Malcolm et al. 2013). Routes of entry into the hair may be the blood vessel that nourishes the hair as it grows, sweat, sebum, conspecifics, and local (i.e. follicular) synthesis (Cone 1996). Hair steroids have been shown to be associated with blood, saliva, urine and fecal steroids levels and their metabolites (e.g. Tian et al. 2015). Since hair integrates endogenous compounds as it grows, it reflects gross patterns, allowing inter-individual and population comparisons (Bryan et al. 2015). Ancient human cortisol has been measured in the hair of archaeological mummies (AD550-1532) (Webb et al. 2010) and ancient sterols have been detected in fecal samples $>500$ years old (up to 1000-2000 years old) (Lin 
et al. 1978; Lin \& Connor 2001). Here, we evaluated hair as a possible source of integrated steroids in ancient extinct species. We applied our published method for quantitation of steroids from hair (Koren et al. 2002, 2008; Koren \& Geffen 2009; Di Francesco et al. 2017) on Siberian woolly mammoth hair shaft samples that had been previously utilized by Gilbert et al. $(2007,2008)$ for mitogenome sequencing. Three additional mammoth samples were added to the study for a total of $10 \mathrm{mam}$ moths, and all samples were radiocarbon dated (for details see Gilbert et al. (2007, 2008). Our goal was to validate a method to measure long-term integrated testosterone levels in mammoth hair in order to establish means to gain insight on the life history of extinct species.

\section{MATERIAL AND METHOD}

\section{Sexing}

The sex of five mammoths was anatomically determined. However, only two of the mammoths from Gilbert et al. (2007, 2008) were sexed at sample collection (M1, M3; which were subsequently sexed both anatomically and genomically). Mammoths of unknown sex (Table 1) were analysed using whole-genome shotgun data from previously published studies (Gilbert et al. 2007, 2008; Lynch et al. 2015) following approaches that were previously described (Skoglund et al. 2015; Pečnerová et al. 2017). In order to avoid a bias in mapping due to the presence of nuclear mitochondrial DNA copies (numts), raw sequences were mapped against a merged nuclear-mitochondrial reference consisting of a nuclear genome of the African elephant (Loxodonta africana) generated by the Broad Institute (LoxAfr4) and a mitochondrial genome of a known woolly mammoth ('Krause', DQ188829) (Krause et al. 2006). Sample M25, which was sequenced on the Illumina platform, was mapped using the BWA-backtrack algorithm implemented in BWA 0.7.8 (Li \& Durbin 2010), and the SAMtools 0.1.19 software package (Li et al. 2009) was used to align and generate mapping statistics. The other samples, sequenced on the 454 pyrosequencing platform, were analysed using the BWA-MEM algorithm in BWA 0.7.8 (Li \& Durbin 2010) and SAMtools 1.3 (Li et al. 2009). Only reads passing a mapping quality filter of $\mathrm{MQ}=30$ were considered. The nuclear reference genome originated from a female elephant, thus Y chromosome reference was not available. Instead, the sex was determined by directly comparing the number of reads mapping to chromosome $\mathrm{X}$ and to chromosome 8 , which are of comparable size. The number of mapped reads was normalized by the length of the chromosome sequence. Male mammoths are expected to have only half the number of reads mapping to chromosome $\mathrm{X}$ compared to chromosome 8 (see Table 1), because males only have a single copy of chromosome $\mathrm{X}$ compared to two in the female elephant. Mammoth samples with higher percentages of reads mapping to chromosome $\mathrm{X}$ were designated females.

\section{Steroid extraction and quantitation}

We extracted steroids from individual mammoth hair that was characterized in Gilbert et al. (2007), using our published protocol (Koren et al. 2002, 2008). Hair samples varied in weight and length $(2$ to $>15 \mathrm{~cm})$. To remove external contaminants from the hair surface, we washed each sample twice with water followed by isopropyl alcohol. Brief (i.e. $3 \mathrm{~min}$ ) washing with isopropyl alcohol was validated over a decade ago by Davenport et al. (2006), who showed that it removes contaminants from the outside the hair but does not extract steroids from within the hair shaft. Hair samples were subsequently dried overnight, weighed and placed in glass vials. We used methanol to extract steroids from inside the hair shaft, sonicated and then incubated overnight at $50^{\circ} \mathrm{C}$ with shaking. Next, the methanol was collected and evaporated. Samples were reconstituted in assay diluent supplied with the commercial enzyme-linked immunosorbent assays (ELISA; Salimetrics, Ann Arbor, MI, USA). Testosterone immunoreactivity was quantitated in individual extracts following the manufacturer's recommendations.

To validate the kit, we tested whether serial dilutions of mammoth hair pool showed parallelism with the provided standards (univariate analysis of variance in SPSS; $p=0.11$ ). Linearity was demonstrated between $10-80 \mathrm{mg}$ of hair, corresponding to $60-250 \mathrm{pg} / \mathrm{mL}$ of testosterone standard. The lowest concentration that we detected was $0.91 \mathrm{pg} / \mathrm{mL}$, corresponding $10 \mathrm{mg}$ hair. Salimetrics reported that antibody cross-reactivity was $36.4 \%$ with dihydrotestosterone, $21.02 \%$ with 19 -nortestosterone, $1.9 \%$ with 11-hydroxytestosterone, $1.157 \%$ with androstenedione and $<0.489 \%$ for other steroids. Intra-assay repeatability was $11.1 \%$, determined using three replicates of the pool on the same plate.

We used a permutation test (JMP version 13; https:// www.jmp.com/en_gb/software/data-analysis-software.html; SAS Inc.) to compare testosterone between sexes, and the correlation between geological age and testosterone (RT version 1.03, B.F.J. Manly, University of Otago, New Zealand).

\section{LC-MS/MS validation}

The presence of testosterone in a pooled mammoth hair extract was confirmed with LC-MS/MS using a similar 


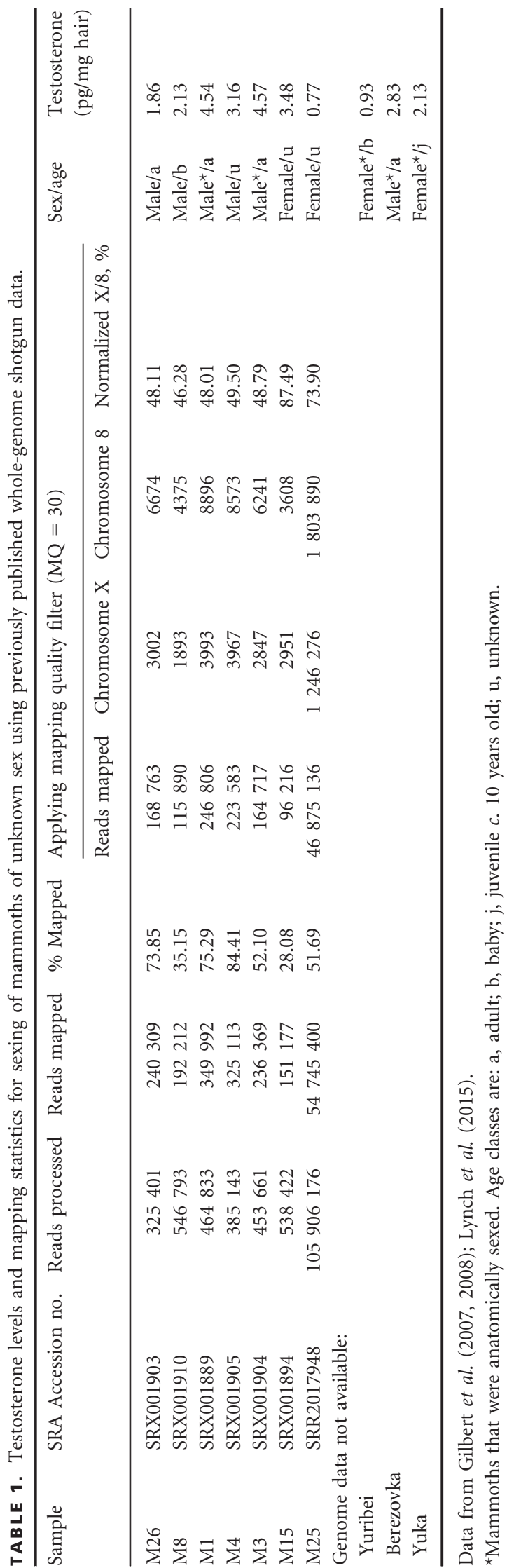

sample preparation method as a recent study of cortisol in muskox qiviut (Di Francesco et al. 2017). The hair pool was gently washed by water for $3 \mathrm{~min}$, rinsed with HPLC grade isopropyl alcohol, dried by paper towel and placed in a fume hood overnight. The sample was then transferred into a $13 \times 100 \mathrm{~mm}$ culture test tube. As an additional validation, another test tube contained $200 \mathrm{mg}$ of the burial matrix that surrounded the individual hair samples. To both test tubes, $100 \mu \mathrm{L}$ of deuterium labeled internal standard solution and $9 \mathrm{~mL}$ cold methanol were added. The test tubes were capped and stored in a $4^{\circ} \mathrm{C}$ fridge for $20 \mathrm{~h}$. After the sample was removed from the test tube, the extract was evaporated to dryness under $\mathrm{N}_{2}$ at $40^{\circ} \mathrm{C}$ using a Techne Sample Concentrator and reconstituted with $150 \mu \mathrm{L} \mathrm{H}_{2} \mathrm{O} / \mathrm{MeOH}(50 / 50$, v/v). The solution was centrifuged at $14000 \mathrm{rpm}$ (Legend micro-21R; Thermo Scientific) for $20 \mathrm{~min}$ and $120 \mu \mathrm{L}$ of supernatant was submitted to LC-MS.

All samples were analysed using an Agilent 1200 binary liquid chromatography (LC) system connected to an $A B$ SCIEX QTRAP ${ }^{\circledR} 5500$ tandem mass spectrometer equipped with an atmospheric pressure chemical ionization (APCI) source. LC separation was performed on an Agilent Poroshell $120 \mathrm{C} 18$ column $(50 \times 3 \mathrm{~mm}, 2.7 \mu \mathrm{m}$ particle size) at $45^{\circ} \mathrm{C}$. The mobile phase $\mathrm{A}$ was $\mathrm{H}_{2} \mathrm{O} /$ $\mathrm{MeOH}(75 / 25, \mathrm{v} / \mathrm{v})$ and the mobile phase $\mathrm{B}$ was $\mathrm{MeOH} /$ IPA $(90 / 10, v / v)$. The $8.5 \mathrm{~min}$ gradient was $20-40 \%$ B (0-1.0 min), 40-60\% B (1.0-5.0 min), 60-100\% B (5.0$5.5 \mathrm{~min}), \quad 100 \% \quad$ B $\quad(5.5-6.5 \mathrm{~min}), \quad 100-20 \% \quad$ B $\quad(6.5-$ $7.0 \mathrm{~min})$, and held at $20 \% \mathrm{~B}(7.0-8.5 \mathrm{~min})$. The flow rate was $0.6 \mathrm{~mL} / \mathrm{min}$ and the injection volume was $20 \mu \mathrm{L}$. The analytes were ionized under positive APCI mode and data were acquired via multiple reaction monitoring (MRM). More details about the quantification protocol are provided in the Koren et al. (2018).

\section{RESULTS AND DISCUSSION}

Using a testosterone-specific antibody in a commercial EIA kit we measured testosterone immunoreactivity in mammoth hair samples that are $10000-60000{ }^{14} \mathrm{C}$ years old. The presence of testosterone in a mammoth hair pool extract was unambiguously verified by liquid chromatography coupled with tandem mass spectrometry (LC-MS/MS; Fig. 1). The LC-MS/MS analysis is highly specific, authenticating the presence of testosterone in mammoth hair pool extract via the time of elution, the deuterated internal standard, and two sequential mass-tocharge $(\mathrm{m} / \mathrm{z})$ transitions. The pooled sample contained hair from unknown individuals from different geographical locations. However, the amount of testosterone that was measured in the pooled sample $(0.38 \mathrm{pg} / \mathrm{mg})$ via LCMS/MS fell within the same order of magnitude as the 

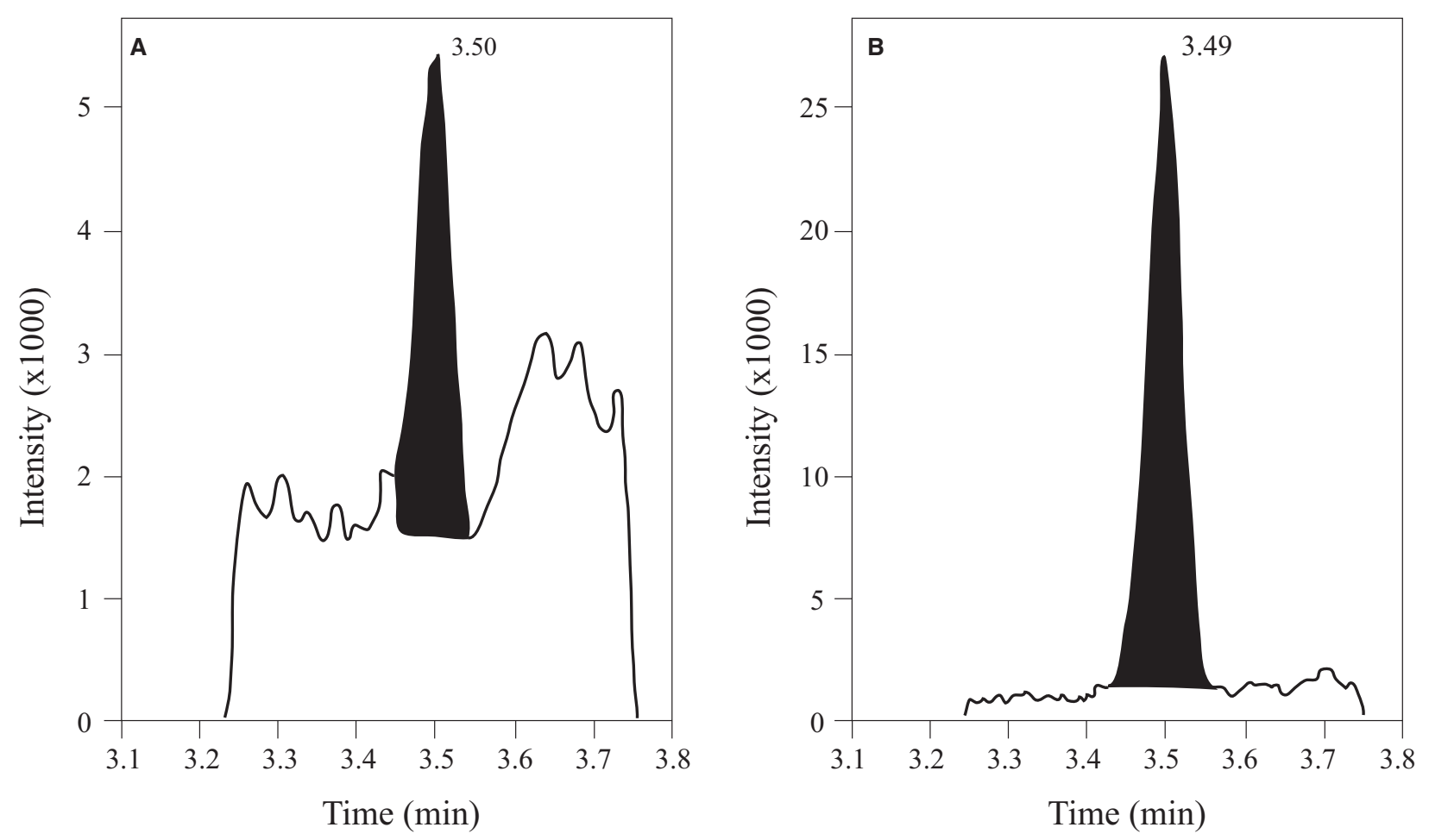

FIG. 1. Chromatograms showing the presence of testosterone (A) and deuterated internal standard (B), in a pooled mammoth hair sample analysed via LC-MS/MS.

testosterone immunoreactivity measured in an individual female's hair sample $(0.77 \mathrm{pg} / \mathrm{mg})$. No testosterone was found in the burial matrix surrounding the hair samples via LC-MS/MS. In addition, the LC-MS/MS detected quantifiable amounts of 17-OH-progesterone, progesterone, DHEA, and androstenedione in the pooled hair sample. Although we have too few cases for statistical tests, we measured testosterone immunoreactivity in all mammoth hair, and sex differences (although not significant; permutation test, $p=0.095)$ in immunoreactive hair testosterone. Mean male $(\mathrm{n}=6)$ hair testosterone levels were $3.18 \mathrm{pg} / \mathrm{mg}$ hair, whereas female $(\mathrm{n}=4)$ were $1.83 \mathrm{pg} / \mathrm{mg}$ hair (Fig. 2). Standard deviations were similar between the two sexes (1.26 in females vs 1.16 in males). Male minimum levels were more than twice those of females' (1.86 pg/mg hair in males compared with $0.77 \mathrm{pg} / \mathrm{mg}$ hair in females) while maximal levels detected for a male was $4.57 \mathrm{pg} / \mathrm{mg}$ hair (vs $3.48 \mathrm{pg} / \mathrm{mg}$ hair for a female). High testosterone is typical of the third trimester pregnancy, and it is thus possible that females with high testosterone were pregnant.

To the best of our knowledge, this study is the first to report testosterone quantitation in a prehistoric extinct species. Although steroids are stable compounds, and the specimens that we used were collected from permafrost deposits in northern Siberia where the environmental conditions support the preservation of steroids in the samples, we observed a declining trend in testosterone over time.

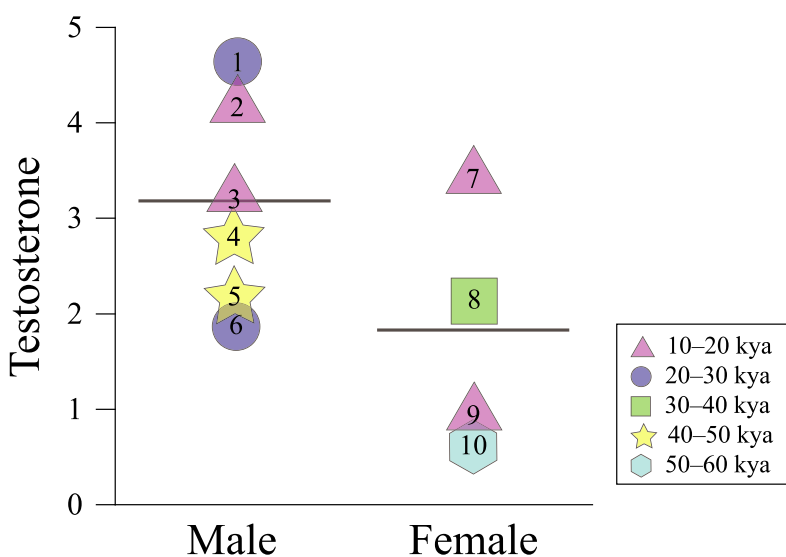

FIG. 2. Hair testosterone ( $\mathrm{pg} / \mathrm{mg}$ hair) in male $(\mathrm{n}=6)$ and female $(n=4)$ woolly mammoths. Colour and shape denotes ${ }^{14} \mathrm{C}$ age. Numbers inside shape denote individual mammoths: 1 , Fishhook (M3); 2, Yukagir (M1); 3, Stephan (M4); 4, Berezovka; 5, Magadan baby (M8); 6, M26; 7, Lacumiu (M15); 8, Yuka; 9, Yuribei; 10, Vanous (M25). Black midlines denote mean testosterone for each sex.

However, the decline was not significant $\left(r^{2}=0.2\right.$, $\beta=-0.00004$, permutation test, $p=0.174$ ), possibly due to the lack of power (least significant number $=22$ ). Controlling for the effect of geological time by the regression residuals showed that the differences in testosterone between the sexes is approaching significance (permutation test, $p=0.074)$. In the African elephant, male 
$(0.38-0.68 \mathrm{ng} / \mathrm{mL})$ and female $(0.14-0.46 \mathrm{ng} / \mathrm{mL})$ circulating testosterone concentrations overlap outside the mating period (Rasmussen et al. 1984). In elephant hair that we ran alongside this study ( $\mathrm{N}=5$; two males, three females), we found similar levels of testosterone to those measured in mammoths (range 0.98-1.94 pg/mg hair; comparable with mammoths in Table 1), suggesting that perhaps testosterone accumulated in a similar manner in both elephant and mammoth hair. In extant Elephantidae, testosterone rises in males to a peak during the musth (Brown et al. 2007; Sukumar 2003), but no seasonal variation is otherwise found in either sex (Brown et al. 2007; McNeilly et al. 1983). Unfortunately, the age classes of three mammoths in our study was unknown. In modern day elephants, testosterone levels are higher in adults than in pre-pubertal males, but no age effects are detected in non-pregnant females (McNeilly et al. 1983). Nonetheless, it is possible that mammoth age is associated with testosterone levels. Clearly, the time period that is reflected in the mammoth hair samples is unknown, and dynamics in testosterone levels in mammoths remain obscure. However, measurements probably represent the last months to a year of the mammoth's life, tens of thousands of years ago, offering novel insight into their lives and possibly their death.

Our results introduce innovative opportunities to quantify multiple steroids in remains of extinct populations of megafauna. These may provide fresh understanding of the ecological conditions that extinct species were subject to. Our method may be extended to other type of keratinized tissue (e.g. feathers, nails, claws, horns, hooves; Koren et al. 2012; Matas et al. 2016). Many remains have already been radiocarbon dated for genetic analysis and may be also used as a source for steroid studies. Hypothetically, measuring glucocorticoid concentrations of a large number of individuals (Di Francesco et al. 2017), over tens of thousands of years, may link changes in physiological processes with major climatic or other environmental changes, and changes in the mean level of population progesterone over time could suggest trends in reproductive output. Moreover, in keratinized tissues with seasonal growth patterns, such as woolly rhinoceros' horns, steroid hormones could even be used to examine seasonal changes in the reproductive biology of extinct species. Despite the challenges involved in this analysis, massive datasets that span tens of thousands of years may yield important information on past periods, through detection of trends in steroid concentrations.

\section{CONCLUSIONS}

The palaeontological assemblages of megafauna from the Quaternary era are suitable for ancient steroid studies due to their pristine preservation and the large number of individuals. Here, we illustrate the feasibility of studying ancient steroids in hair preserved from the permafrost, and the potential for more detailed future studies in this field.

Acknowledgements. The authors are indebted to Dr Ruokun Zhou from the Faculty of Veterinary Medicine at the University of Calgary for verifying the presence of steroids in mammoth hair via LC-MS/MS. We would like to thank three anonymous referees for their comments which have helped improve our paper, and to Sally Thomas for technical reviewing.

Author contributions. LK designed the study, coordinated the study, carried out the analysis, and helped draft the manuscript; DM carried out the molecular lab work, and drafted the manuscript; PP sexed the mammoths; LD, AT, and MTPG collected field data; KEWE carried out the LC-MS/MS analysis and helped to interpret the data, EG conceived of the study and carried out the statistical analyses. All authors gave final approval for publication.

\section{DATA ARCHIVING STATEMENT}

Data for this study are available in the Dryad Digital Repository: https://doi.org/10.5061/dryad.q951rb9

\section{REFERENCES}

BROWN, J. L., SOMERVILle, M., RIDDle, H. S., KEELE, M., DUER, C. K. and FREEMAN, E. W. 2007. Comparative endocrinology of testicular, adrenal and thyroid function in captive Asian and African elephant bulls. General \& Comparative Endocrinology, 151, 153-162.

BRYAN, H. M., SMITS, J. E. G., KOREN, L., PAQUET, P. C., WYNNE-EDWARDS, K. E. and MUSIANI, M. 2015. Heavily hunted wolves have higher stress and reproductive steroids than wolves with lower hunting pressure. Functional Ecology, 29, 347-356.

CONE, E. J. 1996. Mechanisms of drug incorporation into hair. Therapeutic Drug Monitoring, 18, 438-443.

DAVENPORT, M. D., TIEFENBACHER, S., LUTZ, C. K., NOVAK, M. A. and MEYER, J. S. 2006. Analysis of endogenous cortisol concentrations in the hair of rhesus macaques. General \& Comparative Endocrinology, 147, 255-261.

DI FRANCESCO, J., NAVARRO-GONZALEZ, N., WYNNE-EDWARDS, K. E., PEACOCK, S., LECLERC, L. M., TOMASElli, M., DAVISON, T., CARLSSON, A. and KUTZ, S. 2017. Qiviut cortisol in muskoxen as a potential tool for informing conservation strategies. Conservation Physiology, 5, cox052.

DUFTY, A. M. J. 1989. Testosterone and survival: a cost of aggressiveness? Hormones \& Behaviour, 23, 185-193.

GILBERT, M. T., TOMSHO, L. P., RENDULIC, S., PACKARD, M., DRAUTZ, D. I., SHER, A., TIKHONOV, A., DALEN, L., KUZNETSOVA, T., KOSINTSEV, P., CAMPOS, P. F., HIGHAM, T., COLlins, M. J., WILSON, A. S., SHIDLOVSKIY, F., BUIGUES, B., ERICSON, P. G., GERMONPRE, M., GOTHERSTROM, A., 
IACUMIN, P., NIKOLAEV, V., NOWAK-KEMP, M., WILlersleV, E., KNIGHT, J. R., IRZYK, G. P., PERBOST, C. S., FREDRIKSON, K. M., HARKINS, T. T., SHERIDAN, S., MILLER, W. and SCHUSTER, S. C. 2007. Whole-genome shotgun sequencing of mitochondria from ancient hair shafts. Science, 317, 1927-1930.

— DRAUTZ, D. I., LESK, A. M., HO, S. Y., QI, J., RATAN, A., HSU, C. H., SHER, A., DALEN, L., GOTHERSTROM, A., TOMSHO, L. P., RENDULIC, S., PACKARD, M., CAMPOS, P. F., KUZNETSOVA, T. V., SHIDLOVSKIY, F., TIKHONOV, A., WILLERSLEV, E., IACUMIN, P., BUIGUES, B., ERICSON, P. G., GERMONPRE, M., KOSINTSEV, P., NIKOLAEV, V., NOWAK-KEMP, M., KNIGHT, J. R., IRZYK, G. P., PERBOST, C. S., FREDRIKSON, K. M., HARKINS, T. T., SHERIDAN, S., MILLER, W. and SCHUSTER, S. C. 2008. Intraspecific phylogenetic analysis of Siberian woolly mammoths using complete mitochondrial genomes. Proceedings of the National Academy of Sciences, 105, 8327-8332.

KETTERSON, E. D. and NOLAN, V. 1999. Adaptation, exaptation, and constraint: a hormonal perspective. American Naturalist, 154, S4-S25.

KOREN, L. and GEFFEN, E. 2009. Androgens and social status in female rock hyraxes. Animal Behaviour, 77, 233-238.

MOKADY, O., KARASKOV, T., KLEIN, J., KOREN, G. and GEFFEN, E. 2002. A novel method using hair for determining hormonal levels in wildlife. Animal Behaviour, 63, 403-406.

— and GEFFEN E. 2008. Social status and cortisol levels in singing rock hyraxes. Hormones \& Behaviour, 54, 212-216.

- NAKAGAWA, S., BURKE, T., SOMA, K. K., WYNNE-EDWARDS, K. E. and GEFFEN, E. 2012. Nonbreeding feather concentrations of testosterone, corticosterone and cortisol are associated with subsequent survival in wild house sparrows. Proceedings of the Royal Society B, 279, 1560-1566.

— MATAS, D., PEČNEROVÁ, P., DALÉN, L., TIKHONOV, A., GILBERT, M. P. T., WYNNE-EDWARDS, K. E. and GEFFEN, E. 2018. Data from: Testosterone in ancient hair from an extinct species. Dryad Digital Repository. https://doi.org/10.5061/dryad.q951rb9

KRAUSE, J., DEAR, P. H., POLLACK, J. L., SLATKIN, M., SPRIGGS, H., BARNES, I., LISTER, A. M., EBERSBERGER, I., P ÄÄBO, S. and HOFREITER, M. 2006. Multiplex amplification of the mammoth mitochondrial genome and the evolution of Elephantidae. Nature, 439, 724-727.

LI, H. and DURBIN, R. 2010. Fast and accurate long-read alignment with Burrows-Wheeler transform. Bioinformatics, 26, 589-595.

- HANDSAKER, B., WYSOKER, A., FENNELL, T., RUAN, J., HOMER, N., MARTH, G., ABECASIS, G., DURBIN, R. and PROC, G. P. D. 2009. The sequence alignment/map format and SAMtools. Bioinformatics, 25, 20782079.

LIN, D. S. and CONNOR, W. E. 2001. Fecal steroids of the coprolite of a Greenland Eskimo mummy, AD 1475: a clue to dietary sterol intake. American Journal of Clinical Nutrition, 74, 44-49.
— NAPTON, L. K. and HEIZER, R. F. 1978. The steroids of 2000-year-old human coprolites. Journal of Lipid Research, 19, 215-221.

LYNCH, V. J., BEDOYA-REINA, O. C., RATAN, A., SULAK, M., DRAUTZ-MOSES, D. I., PERRY, G. H., MILLER, W. and SCHUSTER, S. C. 2015. Elephantid genomes reveal the molecular bases of woolly mammoth adaptations to the Arctic. Cell Reports, 12, 217-228.

MALCOLM, K. D., McSHEA, W. J., VAN DEELEN, T. R., BACON, H. J., LIU, F., PUTMAN, S., ZHU, X. and BROWN, J. L. 2013. Analyses of fecal and hair glucocorticoids to evaluate short- and long-term stress and recovery of Asiatic black bears (Ursus thibetanus) removed from bile farms in China. General \& Comparative Endocrinology, 185, 97-106.

MATAS, D., KEREN-ROTEM, T. and KOREN, L. 2016. A method to determine integrated steroid levels in wildlife claws. General \& Comparative Endocrinology, 230, 26-28.

McNeIlly, A. S., MARTIN, R. D., HOdGES, J. K. and SMUTS, G. L. 1983. Blood concentrations of gonadotrophins, prolactin and gonadal steroids in males and in nonpregnant and pregnant female african elephants (Loxodonta africana). Journal of Reproduction \& Fertility, 67, 113-120.

MULLER, M. N. 2017. Testosterone and reproductive effort in male primates. Hormones \& Behaviour, 91, 36-51.

PATERNOSTRO, G. 1994. Longevity and testosterone. Nature, 368, 408.

PEČNEROVÁ, P., DÍEZ-DEL-MOLINO, D., DUSSEX, N., FEUERBORN, T., SETH, J. VON, PLICHT, J. VAN DER, NIKOLSKIY, P., TIKHONOV, A., VARTANYAN, S. and DALÉN, L. 2017. Genome-based sexing provides clues about behavior and social structure in the woolly mammoth. Current Biology, 27, 3505-3510.

RASMUSSEN, L. E., BUSS, I. O., HESS, D. L. and SCHMIDT, M. J. 1984. Testosterone and dihydrotestosterone concentrations in elephant serum and temporal gland secretions. Biology of Reproduction, 30, 352-362.

REED, W. L., CLARK, M. E., PARKER, P. G., RAOUF, S. A., ARGUEDAS, N., MONK, D. S., SNAJDR, E., NOLAN, V. and KETTERSON, E. D. 2006. Physiological effects on demography: a long-term experimental study of testosterone's effects on fitness. American Naturalist, 167, 667-683.

SKOGLUND, P., ERSMARK, E., PALKOPOULOU, E. and DALEN, L. 2015. Ancient wolf genome reveals an early divergence of domestic dog ancestors and admixture into high-latitude breeds. Current Biology, 25, 1515-1519.

SUKUMAR, R. 2003. The living elephants: evolutionary ecology, behavior, and conservation. Oxford University Press, New York, 478 pp.

TIAN, Y., HANG, X., WEIWEN, W., SHIFEI, L., ZHENG, C. and HUIHUA, D. 2015. Determination of endogenous corticosterone in rodent's blood, brain and hair with LCAPCI-MS/MS. Journal of Chromatography B, 26, 7-276.

WEBB, E., ThOMSON, S., NELSON, A., White, C., KOREN, G., RIEDER, M. and VAN UUM, S. 2010. Assessing individual systemic stress through cortisol analysis of archaeological hair. Journal of Archaeological Science, 37, 807-812. 